\title{
STUDY OF COMPLEMENTARY FEEDING PRACTICES AMONG MOTHERS OF CHILDREN AGED SIX MONTHS TO TWO YEARS
}

\author{
Sajini Varghese1, Surya Kandashamparambil Kamalakarababu²
}

${ }_{1}^{1}$ Assistant Professor, Department of Paediatrics, Government Medical College, Kottayam.

${ }^{2}$ Assistant Professor, Department of Paediatrics, Government Medical College, Kottayam.

\section{BACKGROUND}

ABSTRACT

Malnutrition remains one of the main public health problems in India. More than half ( 54 percent) of all deaths before the age five in India is related to malnutrition. The World Health Organization (WHO) recommends exclusive breastfeeding for the first six months of life, with the addition of complementary feeds at six months with continued breastfeeds until at least the age of two. Proper breastfeeding and complementary feeding practices can prevent under five mortality by $19 \%$.

\section{MATERIALS AND METHODS}

This hospital-based cross-sectional study was conducted at Institute of Child Health, Government Medical College, Kottayam. Mothers of children between six and twenty four months of age who attended paediatric department were included in this study. Information on selected sociodemographic profile and complementary feeding practices were collected. Chi-square test was used to find the association between complementary feeding and various study parameters.

\section{RESULTS}

Exclusive breastfeeding was practised by $69 \%$ of mothers. Timely initiation of complementary feeding was practised by $65.5 \% .49$ babies were given early initiation of complementary feeding. Only 10\% mothers practised delayed initiation of complementary feeding. Home cereal was preferred by majority (64\%) of study population.

\section{CONCLUSION}

Majority of mothers were practising timely initiation of complementary feeding. Female literacy and socioeconomic status of the family are significantly associated with time of initiation of complementary feeding.

\section{KEYWORDS}

Complementary Feeding Practices, Female Literacy, Malnutrition.

HOW TO CITE THIS ARTICLE: Varghese S, Kamalakarababu SK. Study of complementary feeding practices among mothers of children aged six months to two years. J. Evolution Med. Dent. Sci. 2017;6(94):6872-6876, DOI: 10.14260/jemds/2017/1489

\section{BACKGROUND}

Malnutrition remains one of the main public health problems in India. As per National Family Health Survey (NFHS-3), forty-three percent of children below five years of age are underweight. ${ }^{1}$ Malnutrition is an important factor contributing to the death of young children. More than half (54 percent) of all deaths before the age five in India is related to malnutrition. Optimal infant and young child feeding (IYCF) practices are very important in reducing malnutrition and mortality of children less than 5 years of age. In 2008, the World Health Organization published a standard set of recommended feeding practices for infants and young children, based on the recommendations of the WHO Global Consensus Meeting on Indicators of Infant and Young Child Feeding. ${ }^{2}$

WHO/UNICEF have emphasised the first 1000 days of life i.e., the 270 days in-utero and the first two years after birth as the critical window period for nutritional interventions. As the maximal brain growth occurs, malnutrition in this critical period can lead to stunting and suboptimal developmental

'Financial or Other Competing Interest': None.

Submission 03.11.2017, Peer Review 27.11.2017,

Acceptance 04.12.2017, Published 18-12-2017.

Corresponding Author:

Dr. Sajini Varghese,

Assistant Professor,

Department of Paediatrics,

Government Medical College, Kottayam

E-mail: drsajinidileep@yahoo.co.in

DOI: $10.14260 /$ jemds $/ 2017 / 1489$ outcome. ${ }^{3}$ Infants are at risk of increased malnutrition from six months onwards, when breast milk alone is insufficient in meeting their calorie requirements. ${ }^{4,5}$

The World Health Organization (WHO) recommends exclusive breastfeeding for the first six months of life with the addition of complementary feeds at six months with continued breastfeeds until at least the age of two. ${ }^{4,5}$ Complementary feeding is defined as the process starting when breast milk alone is no longer sufficient to meet the nutritional requirements of infants, and therefore other foods and liquids are needed, along with breast milk. ${ }^{3}$ It is the period of transition from breast milk or breast milk substitute to family foods, and entails introducing a range of foods gradually until the baby is eating the same foods as the rest of the family. Initiating complementary feeds too early or too late can lead to malnutrition.4,6 Various factors like maternal age, maternal education, employment and socioeconomic status can affect the time of initiation of complementary feeding. ${ }^{7}$ It has been found that educated mothers and those from high socioeconomic status are practising timely initiation of complementary feeding. ${ }^{8}$ The early introduction of complementary feeds before the age of six months can lead to displacement of breast milk and increased risk of infections such as diarrhoea, which further contributes to weight loss and malnutrition. ${ }^{9}$ Starting complementary foods too late is also a risk because the child does not receive the extra food required to meet his/her growing needs, the child's growth and development slows down or stops and thus increases risk of malnutrition. The most common reason given for the delayed introduction of 
complementary feed was mothers felt their milk was enough for baby. ${ }^{9}$

Appropriately thick homogenous complementary foods home-made from locally available foods should be introduced at six completed months while continuing breastfeeding ad libitum. ${ }^{10,11}$ The food should be a balanced diet consisting of various (as diverse as possible) food groups/components in different combinations. Easily available, cost-effective, green and other dark coloured vegetables, milk and milk products, pulses/legumes, animal foods, oil/butter, sugar/jaggery may be added in the staples gradually. To provide more calories from smaller volumes, food must be thick in consistencythick enough to stay on the spoon without running off, when the spoon is tilted. ${ }^{11}$

According to National Family Health Survey-3 data, about 20 million children are not able to receive exclusive breastfeeding (EBF) for the first six months, and about 13 million do not get good, timely and appropriate complementary feeding along with continued breastfeeding. ${ }^{1}$ Proper breastfeeding and complementary feeding practices can prevent under five mortality by $19 \% .12$

Although complementary feeding is a universal practice, the methods and manners in which it is practised vary between cultures, individuals, different regions and socioeconomic classes. The present study attempts to find out various complementary feeding practices among mothers of children aged 6-24 months.

\section{Objectives}

To assess the complementary feeding practices among mothers of children aged six months to twenty four months.

\section{MATERIALS AND METHODS}

This hospital-based cross-sectional study was conducted at Institute of Child Health, Government Medical College, Kottayam. Mothers of children between six and twenty four months of age who attended paediatric department of the abovementioned hospital for growth monitoring, immunisation and minor illnesses were included in this study. The protocol was approved by the Institutional Research Committee and ethical board. Semi-structured Proforma was made. Consent was taken from the mothers. Mothers of babies with congenital defects like cleft lip/cleft palate and infants suffering from chronic diseases were excluded from the study. Mothers of selected children who were willing to participate in the study were interviewed for collecting the desired information.

The study was undertaken over a two-month period from September 2017 to October 2017. 200 mothers were enrolled in this study. Information on sociodemographic profile; age of the mother, age of the baby (in months) and weight of the infant, type of family, number of children in the family, socioeconomic status, educational status and occupational status of the mother were collected. Information on complementary feeding practices such as initiation of complementary feeding, type of complementary food was collected.

Information about age at start of complementary feeding (Months), and reasons for giving complementary feeding were collected. Time of initiation of complementary feed by the mother was compared with the recommended time of six months to decide if the feed was early, timely or delayed. Adequacy of the feed was interpreted based on the amount of complementary feed the child received and the meal frequency. Socioeconomic status was assessed using modified Kuppuswamy's scale.13 The variables used in modified Kuppuswamy's socioeconomic scale were education and occupation of the respondent and family income per month in rupees.

Data were entered in Microsoft Excel Sheet and analysed using SPSS version 24. Description of study parameters were given in frequency and percentages. Chi-square test was used to find the association between time of initiation of complementary feeding and various study parameters. $\mathrm{P}$ value less than 0.05 were considered as statistically significant.

\section{RESULTS}

200 mothers were participated in this study. Sociodemographic characteristics of the study population are given in Table 1 . Of the 200 , the majority (42.5\%) of mothers were between 25-30 years age group. $48.5 \%$ children belonged to the 12-18 months age category.

\begin{tabular}{|c|c|}
\hline \multicolumn{2}{|c|}{ Age of Mother (years) } \\
\hline$<20$ & $4(2 \%)$ \\
\hline $20-25$ & $46(23 \%)$ \\
\hline $25-30$ & $85(42.5 \%)$ \\
\hline $30-35$ & $49(24.5 \%)$ \\
\hline$>35$ & $16(8 \%)$ \\
\hline \multicolumn{2}{|c|}{ Age of Children (Months) } \\
\hline$>6-12$ & $69(34.5 \%)$ \\
\hline $12-18$ & $97(48.5 \%)$ \\
\hline $18-24$ & $35(17 \%)$ \\
\hline \multicolumn{2}{|c|}{ Gender } \\
\hline Male & $119(59.5 \%)$ \\
\hline Female & $81(40.5 \%)$ \\
\hline \multicolumn{2}{|l|}{ Type of Family } \\
\hline Nuclear & $114(57 \%)$ \\
\hline Joint & $86(43 \%)$ \\
\hline \multicolumn{2}{|c|}{ Number of children } \\
\hline 1 & $82(41 \%)$ \\
\hline 2 & $108(54 \%)$ \\
\hline 3 or more & $10(5 \%)$ \\
\hline \multicolumn{2}{|c|}{ Mother's literacy status } \\
\hline Up to middle school & $4(2 \%)$ \\
\hline SSLC & $56(28 \%)$ \\
\hline Plus two & $36(18 \%)$ \\
\hline Degree & $76(38 \%)$ \\
\hline Professional & $28(14 \%)$ \\
\hline \multicolumn{2}{|c|}{ Socioeconomic status } \\
\hline Upper & $19(9.5 \%)$ \\
\hline Upper middle & $77(38.5 \%)$ \\
\hline Lower middle & $76(38 \%)$ \\
\hline Lower & $28(14 \%)$ \\
\hline \multicolumn{2}{|c|}{ Mother's occupation } \\
\hline Housewife & $168(84 \%)$ \\
\hline Employed & $32(16 \%)$ \\
\hline
\end{tabular}

More than half of the children were boys; i.e. 119 (59.5\%) were male children and $81(40.5 \%)$ were female. Most of the mothers i.e. 168 (84\%) were homemakers and majority (57\%) belonged to nuclear family. $38 \%$ of the mothers were degree holders and constituted the majority. Mothers who were having middle school education, SSLC, plus two and professionals constituted $2 \%, 28 \%, 18 \%$ and $14 \%$ 
respectively. The socioeconomic status of the 200 mothers according to Kuppuswamy's socioeconomic scale showed that $9.5 \%$ mothers belonged to upper class, 38.5\% belonged to upper middle class and $38 \%$ mothers belonged to lower middle class and rest 14\% from lower class.

\begin{tabular}{|c|c|}
\hline \multicolumn{2}{|c|}{ Six Months of Exclusive Breastfeeding } \\
\hline Practised & $138(69 \%)$ \\
\hline Not practised & $62(31 \%)$ \\
\hline Initiation of complementary feeding \\
\hline Early & $49(24.5 \%)$ \\
\hline Timely & $131(65.5 \%)$ \\
\hline Delayed & $20(10 \%)$ \\
\hline Breastfeeding continued after initiation \\
of complementary feeds \\
\hline Continued & $156(78 \%)$ \\
\hline Stopped & $44(22 \%)$ \\
\hline Type of complementary feed & $128(64 \%)$ \\
\hline Home cereal alone & $72(36 \%)$ \\
\hline Commercial and home cereal & $158(79 \%)$ \\
\hline \multicolumn{2}{|c|}{ Amount of complementary feed } \\
\hline Adequate & $42(21 \%)$ \\
\hline Not adequate & Table 2. Feeding Practices Adopted by Mothers \\
\hline
\end{tabular}

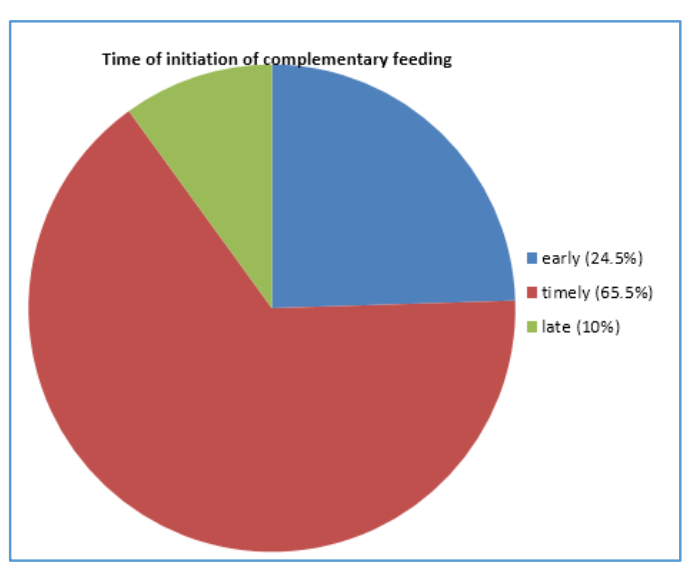

Figure 1

Feeding practices adopted by the mothers is shown in Table 2. Exclusive breastfeeding was practised by $69 \%$. And 156 mothers were still continuing breastfeeding though all the babies were getting complementary feeds. Timely initiation was practised by $65.5 \%$ of mothers (Figure 1). 49 mothers started early complementary feeding. Only 10\% mothers practised delayed initiation of complementary feeding. Home cereal was preferred by majority (64\%) of study population. (Figure 2). Whereas $36 \%$ babies were given both commercial and home cereals.

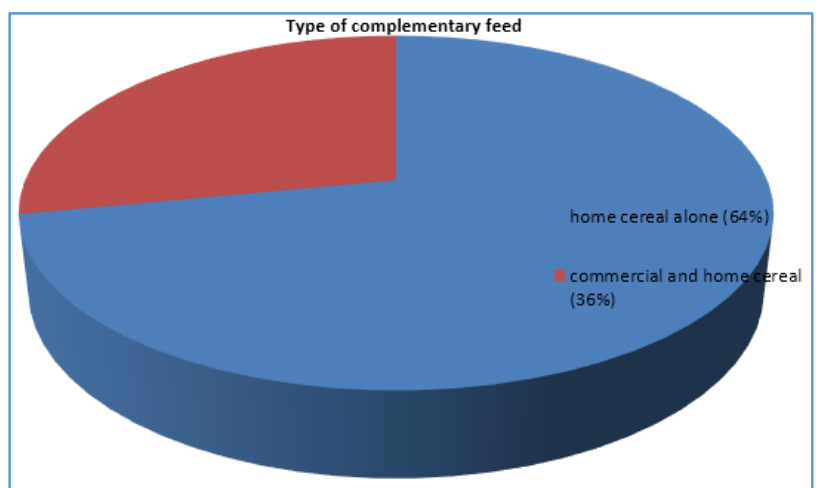

Figure 2. Type of Complementary Feeding

\begin{tabular}{|c|c|c|c|c|}
\hline \multirow[t]{2}{*}{ Factors } & \multicolumn{3}{|c|}{$\begin{array}{l}\text { Initiation of Complementary } \\
\text { Feeding }\end{array}$} & \multirow{2}{*}{$\begin{array}{c}p \\
\text { value }\end{array}$} \\
\hline & Early & Timely & Delayed & \\
\hline \multicolumn{4}{|c|}{ Gender } & \multirow{3}{*}{0.092} \\
\hline Male & $33(27.7 \%)$ & $71(59.6 \%)$ & $15(12.6 \%)$ & \\
\hline Female & $16(19.7 \%)$ & $60(74.07 \%)$ & $5(6.1 \%)$ & \\
\hline \multicolumn{4}{|c|}{ Type of family } & \multirow{3}{*}{0.925} \\
\hline Nuclear & $31(27 \%)$ & $71(62.2 \%)$ & $12(10.5 \%)$ & \\
\hline Joint & $18(20.9 \%)$ & $60(69.7 \%)$ & $8(9.3 \%)$ & \\
\hline \multicolumn{4}{|c|}{ Number of children } & \multirow{4}{*}{0.024} \\
\hline One & $27(32.9 \%)$ & $51(62.1 \%)$ & $4(4.8 \%)$ & \\
\hline Two & $20(18.5 \%)$ & $72(66.6 \%)$ & $16(14.8 \%)$ & \\
\hline $\begin{array}{l}\text { Three and } \\
\text { more }\end{array}$ & $2(20 \%)$ & $8(80 \%)$ & 0 & \\
\hline \multicolumn{4}{|c|}{ Literacy status of mother } & \multirow{6}{*}{0.43} \\
\hline Middle school & 0 & $2(50 \%)$ & $2(50 \%)$ & \\
\hline SSLC & $15(26.7 \%)$ & $35(62.5 \%)$ & $6(10.7 \%)$ & \\
\hline Plus two & $11(30.5 \%)$ & $19(52.7 \%)$ & $6(16.6 \%)$ & \\
\hline Degree & $17(22.3 \%)$ & $57(75 \%)$ & $2(2.6 \%)$ & \\
\hline Professional & $6(21.4 \%)$ & $22(78.5 \%)$ & 0 & \\
\hline \multicolumn{5}{|c|}{ Mother's Occupation } \\
\hline Housewife & $39(23.2 \%)$ & $\begin{array}{c}111 \\
(66.06 \%)\end{array}$ & $18(10.7 \%)$ & \multirow{2}{*}{0.517} \\
\hline Employed & $10(31.25 \%)$ & $20(62.5 \%)$ & $2(6.25 \%)$ & \\
\hline \multicolumn{4}{|c|}{ Socioeconomic status } & \multirow{5}{*}{0.046} \\
\hline Upper & $5(26.3 \%)$ & $12(63.15 \%)$ & $2(10.5 \%)$ & \\
\hline Upper middle & $16(20.77 \%)$ & $55(71.4 \%)$ & $6(7.7 \%)$ & \\
\hline Lower middle & $21(27.63 \%)$ & $49(64.4 \%)$ & $6(7.89 \%)$ & \\
\hline lower & $7(25 \%)$ & $12(42.8 \%)$ & $9(32.14 \%)$ & \\
\hline \multicolumn{4}{|c|}{$\begin{array}{c}\text { Table 3. Factors Associated with Initiation o } \\
\text { Complementary Feeding }\end{array}$} & \\
\hline
\end{tabular}

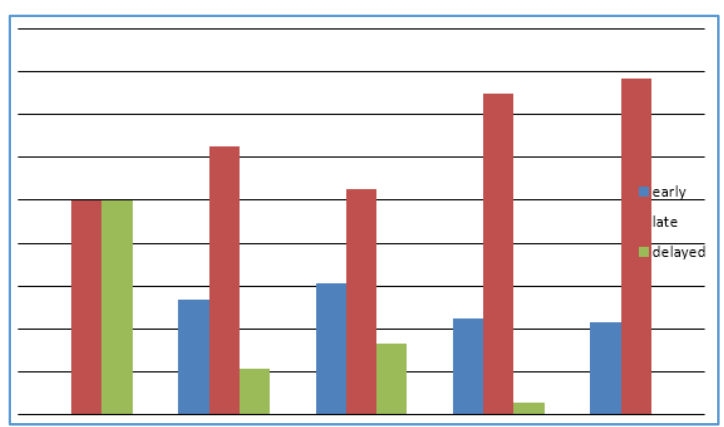

Figure 3. Literacy Status of the Mother and Time of Initiation of Complementary Feeding

Timely initiation of complementary feeding was practised by $75 \%$ of mothers having degree. Whereas among those having professional degree $78 \%$ initiated timely complementary feeding. Majority of mothers having only middle school education initiated complementary feeding very late. (Figure 3). The association of literacy and initiation of complementary feeds at the recommended time was statistically significant $(\mathrm{p}=0.043)$.

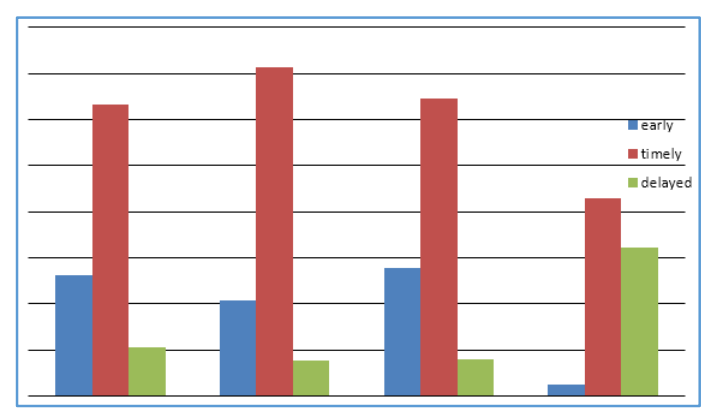

Figure 4. Socioeconomic Status of the Mother and Time of Initiation of Complementary Feeding 
Majority of mothers from upper class and middle class practised timely initiation of complementary feeding. Whereas delayed initiation of complementary feeding was observed in $32 \%$ of mothers from lower socioeconomic status. (Figure 4). This association between socioeconomic status and time of initiation of complementary feeding was significant $(\mathrm{P}<0.05)$ (Table 3$)$.

The mothers with two or more number of children were starting the complementary feed at the recommended time of six months compared to mothers with one baby and the association of number of children and the practice of initiation of complementary feeding at the recommended time was statistically significant $(p=0.024)$.

We analysed the association between time of initiation of complementary feeding and type of family and no statistically significant association was obtained. ( $\mathrm{p}$ value $<0.05$ ). Also, no significant association was identified with the occupation of the mother with initiation of complementary feeding.

\section{DISCUSSION}

Timely introduction of complementary feeding plays an important role in growth \& development of a child. In the present study, $65.5 \%$ of mothers had started complementary feeding at the recommended time i.e., at six months. This is similar to the study done by Rao et al where $77.5 \%$ mothers had done timely initiation of complementary feeding. 8 In another study from Mumbai, 95\% of mothers had started complementary feeding at the recommended time. ${ }^{14} \mathrm{~A}$ prospective interview study of 200 parents by Aggarwal et al showed that only $17.5 \%$ of mothers had started complementary feeding at the recommended time. ${ }^{6}$ Study done by Mridula Bandyopadhyay showed that majority of babies received supplementary food within 6 months of age. 15

Higher rates of timely initiation of complementary feeding in our study may be due to higher female literacy rate in Kerala as most of our mothers were degree holders. The correct timing of complementary feeding significantly correlated to maternal education. $24.5 \%$ of mothers initiated complementary feeding early. Rao et al also observed literate mothers were starting the complementary feeds at the recommended time compared to illiterate mothers. ${ }^{8}$ Another Indian study points out correct timing of complementary feeding significantly correlated to maternal education and father's education. ${ }^{6}$ The reason for early initiation of complementary feeding study were lack of knowledge, inadequate breast milk and elder's advice.

Majority of our study population was in the upper middle class followed by lower middle class. In the upper middle class, $71.4 \%$ mothers had started complementary feeding at the recommended time. Other Indian studies also identified statistically significant association between time of initiation of complementary feeding and socioeconomic status.6,8 In another Indian study, working and higher educated mothers were more aware of initiation of complementary feeding at 6 months. ${ }^{16}$

In our study, the mothers with two or more number of children were starting the complementary feed at the recommended time of six months. This is in contrast to the study done by Rao et $\mathrm{al}^{8}$ where mothers with lesser number of children had initiated complementary feeding at the right time. Our study could not identify any significant association between the time of initiation of complementary feeding and gender of the baby, type of family and occupation of the mother.

WHO recommends Exclusive breastfeeding for the first Six Months. From the total of 200 mother-child pairs who participated in the study, 138 (69\%) children were exclusively breastfed. Kavitha et al in a study conducted in Kerala noted $28 \%$ children were not exclusively breastfed. ${ }^{16}$ Majority of the mothers in our study were continuing breastfeeding along with complementary feeding.

Adequate amount of complementary feeds means foods that provide sufficient energy, protein, and micronutrients to meet a growing child's nutritional needs. ${ }^{4} 79 \%$ children in this study had received adequate amount of complementary feeding.

\section{CONCLUSION}

This study showed that timely initiation of complementary feeding was practised by two third of the mothers. Less than a quarter of the women initiated complementary feeding early. Female literacy and socioeconomic status of the family are associated with timely initiation of complementary feeding.

\section{REFERENCE}

[1] NFHS3 (National Family Health Survey 3, NFHS-3 India Full Report Vol I:pp 269-70. http://www.rchiips.org/nfhs/NFHS-3\%20Data/VOL1/India_volume_I_corrected_17oct08.pdf.

[2] World Health Organization. Indicators for assessing infant and young child feeding practices: conclusions of a consensus meeting held 6-8 November 2007 in Washington, DC, USA. Geneva: World Health Organization, 2008.

[3] Dewey K, Lutter C. Guiding principles for complementary feeding of the breastfed child. Washington DC, USA: PAHO/WHO, Division of Health Promotion and Protection/Food and Nutrition Program; 2003. Accessed September 15, 2015.

[4] World Health Organization. Global strategy for infant and young child feeding. Geneva, WHO, 2003. Available from: http://www.who.int/nutrition/publications/infantfee ding/i nfant feeding.

[5] World Health Organization. Complementary feedingReport of the global consultation Summary of Guiding principles Geneva, 2001. Available from: www.who.int/entity/nutrition/publications/infantfee ding/Complementary_Feeding.pdf.

[6] Aggarwal A, Verma S, Faridi M, et al. Complementary feeding reasons for inappropriateness in timing, quantity and consistency. Indian $\mathrm{J}$ Pediatr 2008;75(1):49-53.

[7] Medhin G, Hanlon C, Dewey M, et al. Prevalence and predictors of undernutrition among infants aged six and twelve months in Butajira, Ethiopia: the P-MaMiE birth cohort. BMC Public Health 2010;10:27.

[8] Rao S, Swathi PM, Unnikrishnan B, et al. Study of complementary feeding practices among mothers of children aged six months to two years-a study from coastal south India. Australa Med J 2011;4(5):252-7. 
[9] The breastfeeding promotion network of India. Introducing solids (Complementary Feeding). Available from: http://www.bpni.org/breastfeeding/introcomplemen try_feeding.html.

[10] Report of the expert consultation of the optimal duration of exclusive breastfeeding. Geneva: World Health Organization; 2001.

[11] Family Nutrition Guide. Burgess A, Glasauer P. Rome: Publishing Management Service, Information Division, Food and Agriculture Organization, Viale delle Terme di Caracalla; 2004

[12] Jones G, Steketee RW, Black RE, et al. How many child deaths can we prevent this year? Lancet 2003;362(9377):65-71.

[13] Kumar N, Shekhar C, Kumar P, et al. Kuppuswamy's socioeconomic status scale-updating for 2007. Indian J Pediatr 2007;74(12):1131-2.
[14] Parekh C, Bavdekar SB, Shaharao V. Study of infant feeding practices: factors associated with faulty feeding. J Trop Pediatr 2004;50(5):306-8.

[15] Bandyopadhyay M. Impact of ritual pollution on lactation and breastfeeding practices in rural West Bengal, India. Int Breastfeed J 2009;4:2.

[16] Pansari VK, Sehra RN, Verma S, et al. A study of feeding practices in the babies of urban educated mothers attending well baby clinic of a tertiary care maternity hospital. National Journal of Research in Community Medicine 2017;6(2):129-34.

[17] Pavithran K, Aalinkeel AK, Payora R. Infant feeding practices in a well-baby clinic of a tertiary hospital in north Kerala. JMSCR 2016;4(6). 